\title{
Early failure of bioprostheses caused by adhesion of preserved leaflets after chordal-sparing mitral valve replacement
}

\author{
Jason O. Robertson, BS, ${ }^{a, b}$ Amir K. Durrani, BS, ${ }^{a, b}$ and Tomislav Mihaljevic, MD, ${ }^{a}$ Cleveland, Ohio
}

$\mathrm{P}$ reservation of the subvalvular apparatus during mitral valve replacement (MVR) was originally suggested by Lillehei and colleagues ${ }^{1}$ in 1964 , and the superiority of this approach over MVR with chordal resection has been demonstrated. ${ }^{2}$ Several different techniques may be used to preserve the mitral leaflets; however, complete preservation of 1 or both leaflets is associated with valvular thrombosis, which may require early explantation. ${ }^{3}$ We report 2 cases of an additional complication to such an approach: severe mitral stenosis caused by adhesion of the preserved valvular apparatus to the bioprosthesis.

\section{Clinical Summary}

CASE 1. A 77-year-old man with a history of emphysema underwent coronary artery bypass grafting and MVR with a bovine prosthesis to repair myxomatous mitral valve prolapse. Five years later, signs of congestive heart failure developed, and the patient was referred for evaluation. Transthoracic echocardiogram revealed an ejection fraction of $50 \%$, mild dilation of the left atrium, $1+$ mitral regurgitation, and severe prosthetic stenosis with a peak mitral gradient of $28 \mathrm{~mm} \mathrm{Hg}$ and a mean gradient of $16 \mathrm{~mm} \mathrm{Hg}$. There was also right ventricular dilation and severe tricuspid regurgitation with an estimated right ventricular systolic pressure of $66 \mathrm{~mm} \mathrm{Hg}$, consistent with moderately severe pulmonary hypertension. The preoperative coronary angiogram showed a patent saphenous vein graft to the left anterior descending artery and no significant coronary artery disease in the remaining coronary vessels. The decision was made to proceed with MVR.

An extended transseptal incision was used to expose the mitral valve prosthesis. On excision of the prosthesis, we observed that the preserved native anterior leaflet of the mitral valve was entirely adhesed onto the ventricular aspect of the mitral prosthesis, causing a severe stenosis (Figure 1, A). A new pericardial prosthesis (Carpentier-Edwards; Edwards Lifesciences, Irvine, Calif) was fitted to

\footnotetext{
From the Department of Thoracic and Cardiovascular Surgery, ${ }^{\mathrm{a}}$ and Cleveland Clinic Lerner College of Medicine, ${ }^{\mathrm{b}}$ Cleveland Clinic, Cleveland, Ohio.

Received for publication Oct 17, 2007; accepted for publication Jan 6, 2008.

Address for reprints: Tomislav Mihaljevic, MD, Department of Thoracic and Cardiovascular Surgery, Cleveland Clinic, 9500 Euclid Avenue, Desk F24, Cleveland, OH 44195 (E-mail: mihaljt@ccf.org).

J Thorac Cardiovasc Surg 2008;135:1180-1

$0022-5223 / \$ 34.00$

Copyright $(\odot 2008$ by The American Association for Thoracic Surgery doi:10.1016/j.jtcvs.2008.01.015
}

the annulus, and the patient was weaned from cardiopulmonary bypass. The patient underwent a difficult postoperative course with respiratory failure requiring a tracheostomy. The patient was discharged to a chronic care facility on postoperative day 22 , where he died 1 month after the surgery.

CASE 2. A 75-year-old man who underwent MVR and coronary artery bypass grafting 3.5 years earlier presented with asymptomatic severe mitral stenosis. The anterior leaflet was incised and mobilized toward the posterior leaflet during his original surgery. Transthoracic echocardiogram revealed an ejection fraction of approximately $60 \%$; mild left ventricular hypertrophy; $3+$ mitral regurgitation with a centrally directed jet; and severe prosthetic stenosis with a valve area of $0.9 \mathrm{~cm}^{2}$, peak mitral gradient of $39 \mathrm{~mm} \mathrm{Hg}$, and mean gradient of $20 \mathrm{~mm} \mathrm{Hg}$. The preoperative angiogram demonstrated patent coronary grafts.

During the reoperative MVR, we observed severe ingrowth of the remainders of the previously preserved mitral valve leaflets on the ventricular surface of the bioprosthesis (Figure 1, $B$ and $C$ ), similar to that in Case 1. This valve was excised and replaced with a mechanical mitral valve prosthesis (St Jude; St Jude Medical, Inc, St Paul, Minn) per patient preference. The patient was discharged on postoperative day 6 in good condition.

\footnotetext{
Discussion

Recent improvements in bioprosthetic valves and the ability to avoid long-term anticoagulation with their use make bioprostheses an attractive option for valve replacement. Compared with MVR with chordal resection, preservation of the subvalvular apparatus produces better outcomes, improves left ventricular regional wall motion, and helps prevent myocardial rupture..$^{2,4}$

Nevertheless, complete preservation of the mitral leaflets led to xenograft failure in the 2 cases described above. It was apparent that these failures were caused by preserved native leaflets because the chordae were attached to the adhesions and the leaflet anatomy was clarified histologically. This may have been avoided by using an alternate method of preserving the subvalvular apparatus. ${ }^{5} \mathrm{We}$ prefer to detach the anterior leaflet of the valve and retain only 2 small islands that contain the chordae to the anterior and posterior papillary muscles. These islands are then secured with everted pledgeted sutures to the lateral and medial aspects of the mitral annulus. Finally, a neo-annulus is created from the posterior leaflet, sparing the chordae, via plication of the leaflet with pledgeted sutures. With this approach it is unlikely that the valvular apparatus could cause the reported complication.

This report draws attention to the potentially avoidable complication of MVR that is observed with complete preservation of the mitral leaflets. Attention to the possibility of this problem through use of the appropriate surgical technique could prevent some bioprosthetic mitral valve failures.
} 

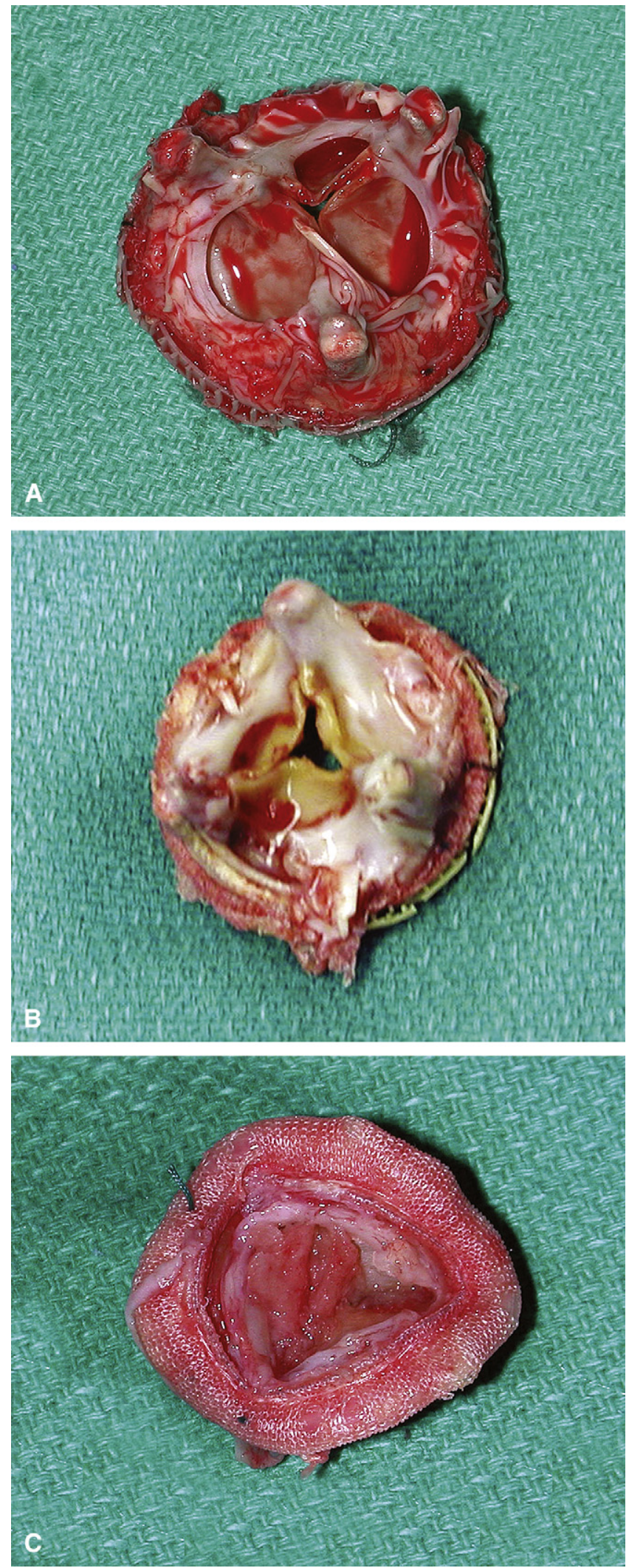

\section{References}

1. Lillehei CW, Levy MJ, Bonnabeau RC Jr. Mitral valve replacement with preservation of papillary muscles and chordae tendineae. J Thorac Cardiovasc Surg. 1964;47:532-43.

2. Natsuaki M, Itoh T, Tomita S, Furukawa K, Yoshikai M, Suda H, et al. Importance of preserving the mitral subvalvular apparatus in mitral valve replacement. Ann Thorac Surg. 1996;61:585-90.

3. Fasol R, Lakew F. Early failure of bioprosthesis by preserved mitral leaflets. Ann Thorac Surg. 2000;70:653-4.

4. Okita Y, Miki S, Ueda Y, Tahata T, Sakai T, Matsuyama K. Mitral valve replacement with maintenance of mitral annulopapillary muscle continuity in patients with mitral stenosis. J Thorac Cardiovasc Surg. 1994;108: 42-51.

5. Smedira NG. Mitral valve replacement with a calcified annulus. Operative Techniques in Thoracic and Cardiovascular Surgery: a Comparative Atlas. 2003;8:2-13.

\footnotetext{
Figure 1. Firm adhesions of native mitral leaflet remnants to bioprosthetic valves and resultant stenosis. A, Ventricular surface of the explanted valve from Case 1. Ventricular (B) and atrial (C) surfaces of the explanted valve from Case 2.
} 